\title{
On Ngסs-Continuous Functions
}

\author{
K. Sakthivel, K.B. Devaki
}

\begin{abstract}
The main goal of this paper is to introduce and investigate the cont. functions of Ngסs-closed sets in NTS with the existing sets and proved some of its results which satisfies the condition.
\end{abstract}

Keywords : Nano topology, Ngסs-cont. functions, contra Ngסs-cont. functions.

\section{INTRODUCTION}

In 1970, Levine[1] introduced the concept of generalized closed sets in topological spaces. The notion of Nano topology was introduced by Lellis Thivagar[2]. The basic definitions are recalled from the following papers which are used to prove our results $[3,4,5,6,7,8,9]$.

Throughout this paper continuous is represented by cont, inverse as invrse, image as imge.

\section{NANO GENERALIZED $\delta$ SEMICLOSED MAPPINGS}

Definition 2.1. A mapping q : C $\rightarrow$ D is called nano generalized $\delta$ semiclosed $(=\mathrm{Ng} \delta$ s-closed $)$ if for each closed

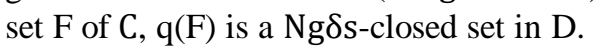

Remark 2.1. Clearly every nano closed map as well as $\mathrm{Ng}$-closed are $\mathrm{Ng} \delta$ s-closed, since every closed set is $\mathrm{Ng}$-closed and every $\mathrm{Ng}$-closed set is $\mathrm{Ng \delta s}$-closed set . Similarly, every nano semiclosed map is Ngסs-closed, since every nano semiclosed set is $\mathrm{Ng} \delta$ s-closed set. The converses are not true in general.

Example 2.1 Let $\mathrm{C}=\{1,2,3,4\}=\mathrm{D}$, then $\tau_{\mathrm{R}}(\mathrm{X})=\{\mathrm{C}, \Phi$, $\{2\},\{1,2,4\},\{1,4\}\}$ and $\tau_{\mathrm{R}}{ }^{\prime}(\mathrm{Y})=\{\mathrm{D}, \Phi,\{2\},\{2,3,4\}$, $\{3,4\}\} . \tau_{\mathrm{R}}(\mathrm{X})=\{\mathrm{C}, \Phi,\{2\},\{1,2,4\},\{1,4\}$ is Ng $\delta$ s -closed map but not nano closed map.

Theorem 2.1. A map q : C $\rightarrow$ D is Ngסs-closed iff for each $S$ $\subset D$ and for each nano open set $X$ containing $q^{-1}(S)$, there is

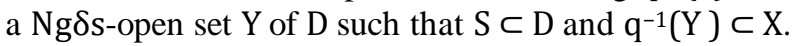

Theorem 2.2. If $\mathrm{q}: \mathrm{C} \rightarrow \mathrm{D}$ is nano cont. and $\mathrm{Ng} \delta$ s-closed and $\mathrm{A}$ is a $\mathrm{Ng}$-closed set of $\mathrm{C}$, then $\mathrm{q}(\mathrm{A})$ is $\mathrm{Ng} \delta$ s-closed.

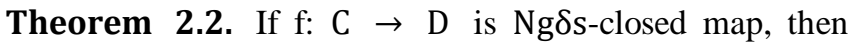
$\operatorname{Ng} \delta \operatorname{scl}(q(A)) \subset q(\operatorname{Ncl}(A))$ for every subset $A$ of $C$.

Revised Manuscript Received on July 08, 2019.

Dr.K. Sakthivel, ${ }^{1}$ Assistant Professor, Department of Mathematics, Government Arts College, Udumelpet-26.

K.B. Devaki, ${ }^{2}$ Assistant Professor, Department of Mathematics, SNMV CAS, Coimbatore-50, Email : devimrudhu@gmail.com
Definition 2.2. A map q : C $\rightarrow$ D is called Ngסs-open if for each nano openset $X$ of $C, q(X)$ is $N g \delta$ s-open set in $D$.

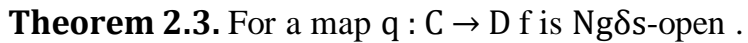

(1) $q(\operatorname{Nint}(A) \subset N g \delta \operatorname{sint}(q(A))$ for each subset $A$ of $C$.

(2) For each $\mathrm{x} \in \mathrm{C}$ and for each nano open set $\mathrm{X}$ containing $\mathrm{x}$, there is a $\mathrm{Ng \delta s}$-open set $\mathrm{Y}$ containing $\mathrm{q}(\mathrm{x})$ such that $\mathrm{YC}$ $\mathrm{q}(\mathrm{X})$.

(3) For each subset $\mathrm{B}$ of $\mathrm{C}, \mathrm{q}^{-1}(\mathrm{Ng} \delta \mathrm{scl}(\mathrm{A})) \subset$ $\operatorname{Ncl}\left(\mathrm{q}^{-1}(\mathrm{~B})\right)$.

Then $(1) \Rightarrow(2) \Rightarrow(3) \Rightarrow(4)$.

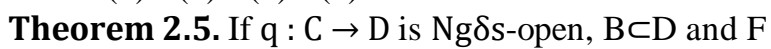
is a nano closed set containing $\mathrm{q}^{-1}(\mathrm{~B})$, then there is a $\mathrm{Ng} \delta$ s-closed set $\mathrm{Y}$ such that $\mathrm{B} \subset \mathrm{Y}$ and $\mathrm{q}^{-1}(\mathrm{Y}) \subset \mathrm{F}$.

\section{$\mathrm{Ng} \delta$ s-cont. function}

Theorem 3.1. A map q : C $\rightarrow$ D is called a Ng $\delta$ s-cont. if $\mathrm{q}^{-1}(\mathrm{D})$ is $\mathrm{Ng} \delta$ s-closed set in $\mathrm{C}$ for every nano closed set $\mathrm{Y}$ of $\mathrm{D}$.

Equivalently, a map q : C $\rightarrow \mathrm{D}$ is $\mathrm{Ng \delta s-cont.} \mathrm{if} \mathrm{and} \mathrm{only} \mathrm{if} \mathrm{the}$ invrse imge of each nano open set is $\mathrm{Ng} \delta$ s-open set

Clearly, every nano cont. map is $\mathrm{Ng}$-cont., every $\mathrm{Ng}$

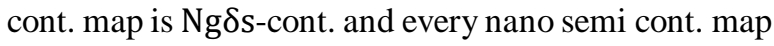
is $\mathrm{Ng} \delta$ s-cont. map.

Example 3.2 From example 2.2, is q(1) is $\mathrm{Ng} \delta$ s-cont. but not $\mathrm{Ng}$ cont.

Theorem 3.2. Let $q: C \rightarrow D$ be a map.

(1) f is Ngסs-cont..

(2) For each $\mathrm{x} \in \mathrm{C}$ and for each nano open set $\mathrm{Y}$ containing $\mathrm{q}(\mathrm{x})$, there is a $\mathrm{Ng \delta s}$-open set $\mathrm{X}$ containing $\mathrm{x}$ such that $\mathrm{q}(\mathrm{X}) \subset \mathrm{Y}$.

(3) $q(\operatorname{Ng} \delta \operatorname{scl}(A)) \subset \operatorname{Ncl}(q(A))$ for each subset A of C.

(4) $\mathrm{Ng} \delta \mathrm{scl}\left(\mathrm{f}^{-1}(\mathrm{~B})\right) \subset \mathrm{f}^{-1}(\mathrm{Ncl}(\mathrm{B}))$ foreachsubsetBofD. Then $(1) \Rightarrow(2) \Rightarrow(3) \Rightarrow(4)$.

Lemma 3.1. If $q: C \rightarrow D$ is nano closed and $\mathrm{Ng} \delta$ s-cont. and $\mathrm{B}$ is a Ng $\delta$ s-closed set of $\mathrm{D}$, then $\mathrm{q}^{-1}(\mathrm{~B})$

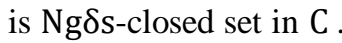

Definition 3.1. A function $\mathrm{q}: \mathrm{C} \rightarrow \mathrm{D}$ is said to be

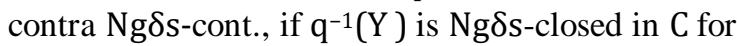
each nano open set $Y$ of $D$.

Remark 3.1. Both contra

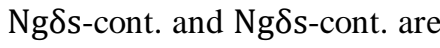




\section{On Ngסs-continuous functions}

independent notions of each other.

Theorem 3.2. If $q: C \rightarrow D$ is contra cont., then it is contra Ngסs-cont..

Remark 3.2. Converse of the above theorem need be true in general.

Theorem 3.3. If $\mathrm{q}: \mathrm{C} \rightarrow \mathrm{D}$ is contra semi cont., then it is

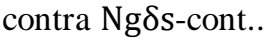

Remark 3.2. Converse of the above theorem need be true in general.

Lemma 3.2. The following properties hold for subsets A and $B$ of a space $C$ :

(1) $x \in \operatorname{ker}(A)$ if and only if $A \cap F \neq \varnothing$ for any nano closed set $F$ of $C$ containing $x$.

(2) $A \subset \operatorname{ker}(A)$ and $A=\operatorname{ker}(A)$ if $A$ is nano open in $C$.

(3) If $A \subset B$, then $\operatorname{ker}(A) \subset \operatorname{ker}(B)$.

Theorem 3.5. The following are equivalent for a function $\mathrm{q}: \mathrm{c} \rightarrow \mathrm{d}$

(4) f is contra Ngסs-cont.

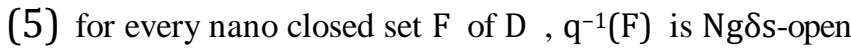
set of $C$.

(6) for each $x \in C$ and each nano closed set $F$ of $D$ containing $\mathrm{q}(\mathrm{x})$, there exists $\mathrm{Ng} \delta$ s-open set $\mathrm{X}$ containing $\mathrm{X}$ such that $\mathrm{q}(\mathrm{X}) \subset \mathrm{F}$.

(7) for each $x \in C$ and each nano open set $Y$ of $D$ not containing $\mathrm{q}(\mathrm{x})$, there exists $\mathrm{Ng} \delta$ s-closed set $\mathrm{K}$ not containing $x$ such that $\mathrm{q}^{-1}(\mathrm{Y}) \subset \mathrm{K}$.

(8) $q(N g \delta s-c l(A)) \subset \operatorname{ker}(q(A))$ for every subset $A$ of $C$.

(9) $\mathrm{Ng} \delta \mathrm{s}-\mathrm{cl}\left(\mathrm{q}^{-1}(\mathrm{~B})\right) \subset \mathrm{q}^{-1}(\operatorname{ker}(\mathrm{B}))$ for every subset $\mathrm{B}$ of $\mathrm{D}$. Theorem 3.6. If a function $\mathrm{q}: \mathrm{C} \rightarrow \mathrm{D}$ is contra $\mathrm{Ng} \delta$ s-cont. and $\mathrm{D}$ is nano regular, then $\mathrm{f}$ is $\mathrm{Ng} \delta$ s-cont..

Theorem 3.7. If a function $\mathrm{q}: \mathrm{C} \rightarrow \mathrm{D}$ is contra $\mathrm{Ng} \delta$ s-cont. and $\mathrm{C}$ is $\mathrm{T}_{\mathrm{Ng} \delta \mathrm{s}}-\mathrm{space}$, then $\mathrm{f}$ is contra nano cont..

Theorem 3.8. If a function $\mathrm{q}: \mathrm{C} \rightarrow \mathrm{D}$ is contra $\mathrm{Ng} \delta$ s-cont. and $\mathrm{C}$ is $\mathrm{Ng} \delta \mathrm{s}-\mathrm{T}_{1 / 2}$ space, then $\mathrm{f}$ is contra nano semi cont..

\section{Conclusion}

In this paper we introduce the new sets in topological spaces Nano generalized $\delta$ semiclosed mappings and its contionous function. And also deals properties of those sets.
8. Revathy. A and G. Illango, On nano $\beta$-open sets, Int. J. Eng. Contemp. Math. Sci. ,1(2)(2015)1 - 6 .

9. Sathishmohan. P, Rajendran. D, Devika. A and Dani. R, On nano semi-continuity and nano pre-continuity, International Journal of Applied Research, 2017,3(2):76 79.

K. Rajalakshmi, C. Vignesh Kumar, V. Rajendran, P. Sathishmohan, Note on contra semipre continuous functions, Indian Journal of Science and Technology, Vol 12(16), 2019.

\section{AUTHORS PROFILE}

Dr.K. Sakthivel, ${ }^{1}$ Assistant Professor, Department of Mathematics, Government Arts College, Udumelpet-26.

K.B. Devaki, ${ }^{2}$ Assistant Professor, Department of Mathematics, SNMV CAS, Coimbatore-50, Email :devimrudhu@gmail.com

\section{REFERENCES}

1. [1] Levine. N, Generalized closed sets in topology, Rend. circ. Math ,Palermo,(2),19,89.

2. [2] Lellis Thivagar and Richard. C, On nano forms of weekly open sets, Int. J. Math. Stat. Invev. 1 (1)(2013) 31 - 37.

3. Lellis Thivagar, Saeid Jafari and Sutha Devi. D, On New Class of Contra Continuity in Nano Topology.

4. Mohammed M, Khalaf and Karal N. Nimer, Nano PS - open sets and Nano PS continuity, International Journal of Contemporaray Mathematical Sciences, Dol. 10, 2015, no. 1, 1 - 11 .

5. Nasef. A, Aggour. A. I and Darwesh. S. M, On some classes of nearly open sets in nano topological space, Journal of Egyptian Mathematical Society, (2016),24, 585589

6. Pawalk. Z, Rough sets, Int. J. Comput. Inf. Sci. 11 (5)(1982) 341 - 356

7. Pawalk. Z, Rough sets, Theoretical Aspects of Reasoning about Data, Kluwer Academic Publishers, Boston, 1991 